\title{
Sustainable evaluation of urban buildings for safety in environment management: the case of the Taiwan 921 earthquake
}

\author{
C.-H. Tu \& K.-W. Tsou \\ Department of Urban Planning, National Cheng Kung University, \\ Taiwan
}

\begin{abstract}
After the 921 earthquake in Taiwan, people have a great fear of earthquakes. In terms of disaster characteristics in earthquakes, the casualties were caused by breakages and the collapse of the buildings. The ability of the building to resist earthquakes becomes a fundamental requirement for earthquake prevention. The factors that influence the ability of a building to resist earthquakes can be categorized into two: the characters of natural environment and the characters of the building itself. The Binary Regression Method was used to construct a forecast model for the hazardousness of the building in an earthquake disaster, and to differentiate the relationship between damage to the building and the characters of the building by the coefficients in the model. In this study, which is in accordance with building damage records of the Gi-Gi earthquake, nine factors, namely the distance between the building and a river, the thickness of the soil, the structure of the building, the number of floors a building has, the age of the building, the use of the building, the plane configuration of the building, any skylights and the situation of any overprint on the roof, are determined in the logistic regression model, and the relationship between these factors and the grades of building damage are also analyzed by the model. In the aspect of model application, this study chooses parts of the areas in the east of Tainan City, which provide similar environmental conditions, calculates the danger probability and transforms these into the building prediction results in safety, danger and collapse. The prediction results are proved credible and valid through examination.
\end{abstract}

Keywords: the building hazard in earthquake disasters, the logistic regression model. 


\section{Introduction}

Earthquake disasters in urban areas usually include three types of hazard: the hazard of buildings during the earthquake, the hazard of fire, and the hazard of refuge and rescue. This study emphasizes the hazards of buildings during earthquakes and establishes a model to reduce the damage caused by earthquakes.

\section{Literature review}

\subsection{The evaluation of earthquake disasters in urban areas}

The evaluation of earthquake disasters is mainly used to compare different areas with different environmental conditions. The following are related researches. In mainland China, the related literature [1-3] is fruitful and includes the discussion of earthquake risk and hazard. In Tokyo, Japan, according to the 17th clause in disaster prevention regulations, the city government should consider the urban conditions and changes, using a scientific method to measure the disaster hazard, and declare the earthquake disaster evaluation to the public in the city. The evaluation detects the causes and the distribution of earthquake disasters, and compares the relative methods of hazard measurements. The items for evaluation $[4,5]$ include the hazard of buildings during earthquakes, the hazard of people, the hazard of fire, and hazard of refuge and rescue.

\subsection{The evaluation of buildings during an earthquake disaster in urban areas}

The accuracy of evaluation, $[1,6]$, is determined by the gap between the expected and perceived levels in the amount, degree and the distribution characteristics of urban damage. A common analysis model of buildings during an earthquake disaster could be as follows.

\subsubsection{Analysis based on the vulnerability of a building to earthquake disasters}

Researchers in Tokyo evaluated the hazard of the middle and low reinforced concrete (RC) buildings and wooden buildings. The criteria contain accuracy and scenario prediction. The indicators for middle and low RC buildings are soil, geology, and building density. The degree of hazard to wooden buildings can be calculated by direct damage from the shake of earthquakes, landsides from excavation and fill soil, the damage degree of a slide, the distribution and number of retaining walls, the number of buildings, the age of the building, and the number of stories in the building $[7,8]$.

In Taiwan, related research [9] is based on the evaluation of the entire urban area and indicated by the building structure category, the style, the plane or 3-D regulations, the roof structure, the age of the building (e.g., the period in which the building was constructed, previous damage from fire or other disasters, 
cracks, erosion, and leakage). Tsai and Chen [10] provided an initial evaluation in detail with RC buildings as a screening method.

\subsubsection{Analysis based on statistical model for prediction}

2.2.2.1 Fuzzy synthetic evaluation method of buildings subject to earthquake disasters This method [11] assumes that the destructiveness scale can show in a curve of normal distribution. There are five scales of destructiveness: normal, slight damage, medium damage, serious damage, and collapse.

2.2.2.2 Stepwise analysis of building damage This method uses the sample of destroyed brick buildings with several stories in Tian-Jin, which happened in the Tang-Shan earthquake. The damage level is then determined using progressive analysis, which is based on the following factors: style of building structure, total height of the building, floor structure, construction mass, the amount of mortar in bearing walls (shear stress of brick wall), the percentage area of brick wall, and the characteristics of soil. The other method is called logistic regression, which has the same functions as progressive analysis without the assumption of normal distribution. This method is widely applied in researches of urban planning, residence, transportation, finance, medicine, psychology and education. It has been quite helpful in risk evaluation in prediction finance and accident damage levels in transportation. Although there is no application in the evaluation of building damage so far, it is expected to be a new research method in the future.

\section{Case study of Jwu-Shan town in Taiwan using the hazard analysis of buildings in an earthquake disaster}

According to the National Center For Research on Earthquake Engineering statistic data, 8733 buildings were damaged in the Taiwan 921 Gi-Gi earthquake. This included 327 buildings in Jwn-Shan town, the damage ratio of which was $37.37 \%$. However, as some damaged buildings' data were not complete, only 166 buildings can be efficient samples. In addition, 752 safety buildings were also included in the survey for this study. Therefore 918 buildings are the total efficient samples.

\subsection{Establishment of damage-degree evaluation model and analysis of the building hazard in earthquake disasters}

\subsubsection{Model design and descriptions of factors}

Data from the investigation results in Jwu-Shan town were divided into two categories: safe or dangerous (buildings that were going to collapse or were already collapsed). The possibility is decided by the hazard of buildings with logistic regression. We use logistic regression in the SPSS package and establish our model in the following. 
$\mathrm{Z}=\mathrm{f}$ (the distance between the building and the fault (-) ((-): the symbolism parentheses indicate predictive variable symbols), the distance between the building and a river (-), the thickness of the soil (-), the structure of the building (?) (structure dummy variables include four kinds of building materials: RB(-), bricks $(+)$, soil $(+)$, and wood $(+))$, the current usage situation $(+)$, the number of floors the building has $(-)$, the period during which the building was constructed $(-)$, the plane configuration of the building $(+)$, the situation of any overprint on the roof $(+)$, any skylights $(+))$.

The distance between the building and fault ( 5 levels), the distance between the building and any river (4 levels), and the period during which the building was constructed ( 5 levels) belong to ordinal factors. The thickness of soil and the number of floors are continuous variables. The structure of the building (5 kinds), the current usage situation ( 2 kinds), the plane configuration of the building ( 2 kinds), the situation of overprint on the roof ( 2 kinds) and the skylight (2 kinds) are nominal variables.

\subsubsection{Variable coefficient test and test of model fitness}

When all the factors above are considered in our model (model 1), the coefficient tests are: a significant distance between the building and the fault, RB structure, whether the building is made of wood, soil or brick $(\mathrm{p}<.1)$. The coefficient of the distance between the building and the fault is significant because of the low power of the small sample. According to the research [8], the distance between the building and the fault should be categorized in three: less than 2 kilometers, between 2 and 5 kilometers, and more than 5 kilometers. Our sample all belonged to the category of less than 2 kilometers, and it leads to an insignificant result. Therefore, we decided to exclude this factor. We form a factor of whether the building is of RB structure or not, because building structures of RB, wood, soil and brick are categorized in the same factor. We used the logistic regression again (model 2) and all of the newly defined factors were significant in the results. The $-2 \mathrm{LL}$ values from models 1 and 2 were 441.136 and 456.781 and the Chi-square value was larger than 18.55 from the table. The null hypothesis that all the coefficients are 0 should be rejected. We used the threshold level 0.5 as the criterion to decide the success or failure of the prediction. Our models 1 and 2 separately showed the accuracy prediction to be $91.07 \%$ and $90.74 \%$, respectively. The difference between model 1 and 2 is not much. However, model 2 has more advantages since it has a fewer numbers of variables and all showed significant results. We decided to use model 2 as the evaluation model of hazard analysis in buildings during an earthquake disaster.

\subsubsection{Explanation of model parameters}

The coefficient of $\mathrm{X}_{2}$ is -1.90 , which means that it has negative influence on our model. In other words, the larger the distance between the building and any rivers, the safer it could be. This matches our prediction. Esp $(\beta 1)=0.1487$ reveals that when doubling the distance from 400 meters to 800 meters, the hazard ratio decreases by $14.87 \%$.

The coefficient of $X_{3}$ is -0.0099 . When the thickness of soil increases, the fewer hazards a building faces. Theoretically speaking, for short buildings, the 
thinner it is, the more dangerous it will be. Most of the buildings in Jwu-Shan town were short ones, which were caused serious damage in the earthquake. The hazard ratio Esp $(\beta 1)$ is 0.9902. It implies that when the thickness of soil increases 1 meter, the hazard ratio decreases by $99.02 \%$.

Table 1: The logistic parameter table of the hazard of building earthquake disasters.

\begin{tabular}{|l|l|l|l|}
\hline \multicolumn{1}{|c|}{ Variable } & Model 1 $\left(\beta_{\mathrm{i}}\right)$ & Model $2\left(\beta_{\mathrm{i}}\right)$ & Esp $\left(\beta_{\mathrm{I}}\right)$ \\
\hline $\begin{array}{l}\text { Intercept item } \\
\text { Distance between the building } \\
\text { and the fault }\left(\mathrm{X}_{1}\right)\end{array}$ & $37.63(0.31)$ & $7.2890^{* *}(69.34)$ & \\
$\begin{array}{l}\text { Distance between the building } \\
\text { and the river }\left(\mathrm{X}_{2}\right)\end{array}$ & $-6.17(0.21)$ & & \\
Thickness of the soil $\left(\mathrm{X}_{3}\right)$ & $-0.01^{* *}(16.58)$ & $-0.009^{* *}(16.42)$ & 0.99 \\
RB structure $\left(\mathrm{X}_{4}\right)$ & $-0.28(0.01)$ & $-0.695^{*}(3.05)$ & 0.49 \\
Brick structure $\left(\mathrm{X}_{5}\right)$ & $0.28(0.01)$ & & \\
Soil structure $\left(\mathrm{X}_{6}\right)$ & $9.40(0.13)$ & & \\
Current usage situation $\left(\mathrm{X}_{7}\right)$ & $-0.45^{*}(3.72)$ & $-0.40^{*}(3.33)$ & 0.66 \\
Number of floors $\left(\mathrm{X}_{8}\right)$ & $-0.45^{* *}(11.81)$ & $-0.47^{* *}(12.83)$ & 0.62 \\
Period of construction $\left(\mathrm{X}_{9}\right)$ & $-0.27^{* *}(6.72)$ & $-0.31^{* *}(9.19)$ & 0.72 \\
Plane configuration of building & $3.98^{* *}(29.27)$ & $3.89^{* *}(28.11)$ & 49.10 \\
$\left(\mathrm{X}_{10}\right)$ & $1.92^{* *}(47.47)$ & $1.89^{* *}(48.24)$ & 6.66 \\
Situation of overprint on the roof \\
$\left(\mathrm{X}_{11}\right)$
\end{tabular}

Remark: 0.9209 is Wald statistical value “*”P $<0.1$, “** " $\mathrm{P}<0.0 .5$.

Data source: originated from this research.

The coefficient of $\mathrm{X}_{4}$ is -0.6956 based on two categories: with $\mathrm{RB}$ or without RB. It shows that the structure of $\mathrm{RB}$ is safer than that of brick, soil or wood. The hazard ratio Esp $(\beta 1)$ is 0.4988 , which means that a structure without RB is twice as hazardous as that with RB.

According to the architect technique regulations, the design of commercial buildings should be more enduring for earthquakes than that of residences. The coefficient of $\mathrm{X}_{7}$ is -0.4554 , which is against the regulations and theoretical explanations. The hazard ratio $\operatorname{Esp}(\beta 1)$ in the model is 0.6697 , which represents the hazard ratio between residential and commercial buildings. In other words, buildings for commercial usage are 149\% more hazardous than those for residential usage. 
The coefficient of $X_{8}$ is -0.4715 , which shows that the higher the number of floors a building has, the safer it could be. This conforms to our expectation. The hazard ratio Esp $(\beta 1)$ in the model is 0.6241 . When the floor number increases by 1 , the hazard ratio decreases by $62.41 \%$.

The period of construction is divided into five categories based on the related regulations. The coefficient of $\mathrm{X}_{9}$ is -0.2775 . The later the construction is, the safer the building is, and our model is consistent with this prediction from theory. From the hazard ratio Esp $(\beta 1) 0.7268$, we realize that when the period of construction increases one level (i.e., from before 1974 to 1974-1982), the hazard ratio is reduced by $72.68 \%$.

The theory says that when plan configuration is non-rectangular (i.e., Пshape or + -shape), the building is more dangerous. The coefficient of $X_{10}$ is 3.8939 , which implies that the non-rectangular plan configuration has a positive impact on our model and is consistent with the theory. The hazard ratio Esp $(\beta 1)$ in the model is 49.1038 and means that non-rectangular buildings are much more dangerous than rectangular ones.

Based on the theory, the overprint of the building leads to disequilibrium of loading and causes danger. The coefficient of $\mathrm{X}_{11}$ is 1.8967 in our model, which supports that buildings with an overprint are indeed more dangerous than those without an overprint. The hazard ratio Esp $(\beta 1)$ in the model of 6.6639 shows that buildings with an overprint are 6.6639 times more dangerous than those without an overprint.

The skylight reduces the power of endurance for the first floor, and leads to collapse or damage during an earthquake. The coefficient of $\mathrm{X}_{12}$ is 6.1911 in our models, which confirms the theory. The hazard ratio Esp ( $\beta 1)$ is 488.3978 , and it tells us that the buildings with skylights can be as much as 488.3978 times more hazardous those without skylights.

\subsection{The categories of hazard ratio in the model}

For applications on urban disaster planning, the hazard ratios of buildings are categorized into three groups: safe, dangerous, and collapse. The categorization criterion is based on the adjustments of danger probability $P$. We get the $Z$ value after data analysis in our model by using the following two formulas.

$$
\begin{gathered}
\mathrm{Z}=\beta_{0} \mathrm{X}_{0}+\beta_{1} \mathrm{X}_{1}+\ldots+\beta_{\mathrm{n}} \mathrm{X}_{\mathrm{n}} \\
\mathrm{P}(\text { danger probability })=\frac{\mathrm{e}^{\mathrm{z}}}{1+\mathrm{e}^{\mathrm{z}}}
\end{gathered}
$$

\subsection{Establishment of the mode}

Based on the data above, the logistic regression model is established as follows:

$$
\begin{aligned}
Z= & 7.289-1.9079 X_{1}-0.0099 X_{2}-0.6956 X_{3}-0.4009 X_{4}-0.4715 X_{5}- \\
& 0.3191 X_{6}+3.8939 X_{7}+1.8967 X_{8}+6.1911 X_{9}
\end{aligned}
$$

$\mathrm{Z}$ : the hazard score

$\mathrm{X}_{1}$ : distance between the building and fault

$\mathrm{X}_{2}$ : thickness of soil 
$\mathrm{X}_{3}: \mathrm{RB}$ structure $(\mathrm{RB}: 1$, non-RB : 0$)$

$\mathrm{X}_{4}$ : current usage situation (residence $: 1$, non-residence $: 0$ )

$\mathrm{X}_{5}$ : floor members of the building

$\mathrm{X}_{6}$ : time of construction

$\mathrm{X}_{7}$ : plane configuration of building (non-rectangle : 1 , rectangle : 0 )

$\mathrm{X}_{8}$ : situation of overprint on roof (overprint : 1 , non-overprint : 0 )

$\mathrm{X}_{9}$ : the skylight (skylight : 1 , non-skylight : 0 )

\section{Applications in the eastern part of Tainan city, Taiwan}

This study surveys a total of 864 buildings in the eastern part of Tainan city, with disaster protection and special ability rescue buildings such as schools, hospitals, factories, temples and churches being excluded, so only 784 buildings are efficient samples. The analysis of building earthquake disaster is as follows.

\subsection{The model operation steps}

The model operation steps are as shown in Figure 1. The steps are as follows.

(1) Insert 784 efficient buildings survey data into Formula 3, and obtain the hazard scores ( $Z$ value).

(2) By Formula 2, transfer and obtain the danger probability (P value).

(3) Use the danger probability in disaster protection planning.

\subsection{The result of the model and description}

According to survey data and Arcview, SPSS and Excel software, the distribution diagram of the scores of hazards of building earthquake disasters in

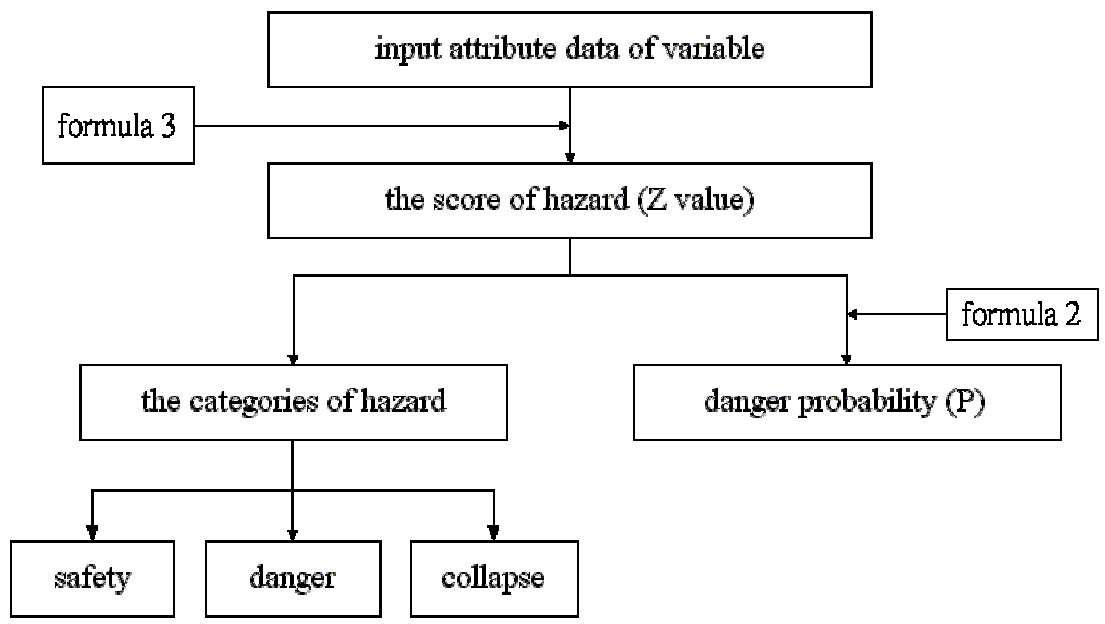

Figure 1: The operation process of the hazard evaluation model for building earthquake disasters. 
the eastern part of Tainan can be obtained. If an optimistic $\mathrm{P}$ value is taken as in Figure $1, \mathrm{P}>0.9$ is collapse, $0.9<\mathrm{P}<0.5$ is danger, $\mathrm{P}<0.5$ means safety. The hazard results of the buildings are shown in Figure 2.

Adding (2) and (3) of the above, there are 194 damaged buildings in total, which constitutes $24.75 \%$. The analysis of the results includes the following: 127 (65.4\%) of the damaged buildings were constructed before 1987, and could possibly cause collapse or danger; there are 78 damaged buildings made of soil and wood (31.3\%); the damaged ratio of the non-rectangular buildings is $44.4 \%$; The damage ratio of rectangular buildings is $24.5 \%$; 78 of the damaged buildings $(31.3 \%)$ were made of soil and wood; the damage ratio of $\mathrm{RB}$ buildings is comparatively lower than the buildings of other materials, which is $14.5 \%$; the soil buildings are least resistant to earthquakes, the damage of which is $100 \%$ (danger $66.7 \%$ + collapse $33.3 \%$ ); the brick and wood buildings are next to $\mathrm{RB}$, the damage ratio of which are discretely $24.4 \%$ and $53 \%$.

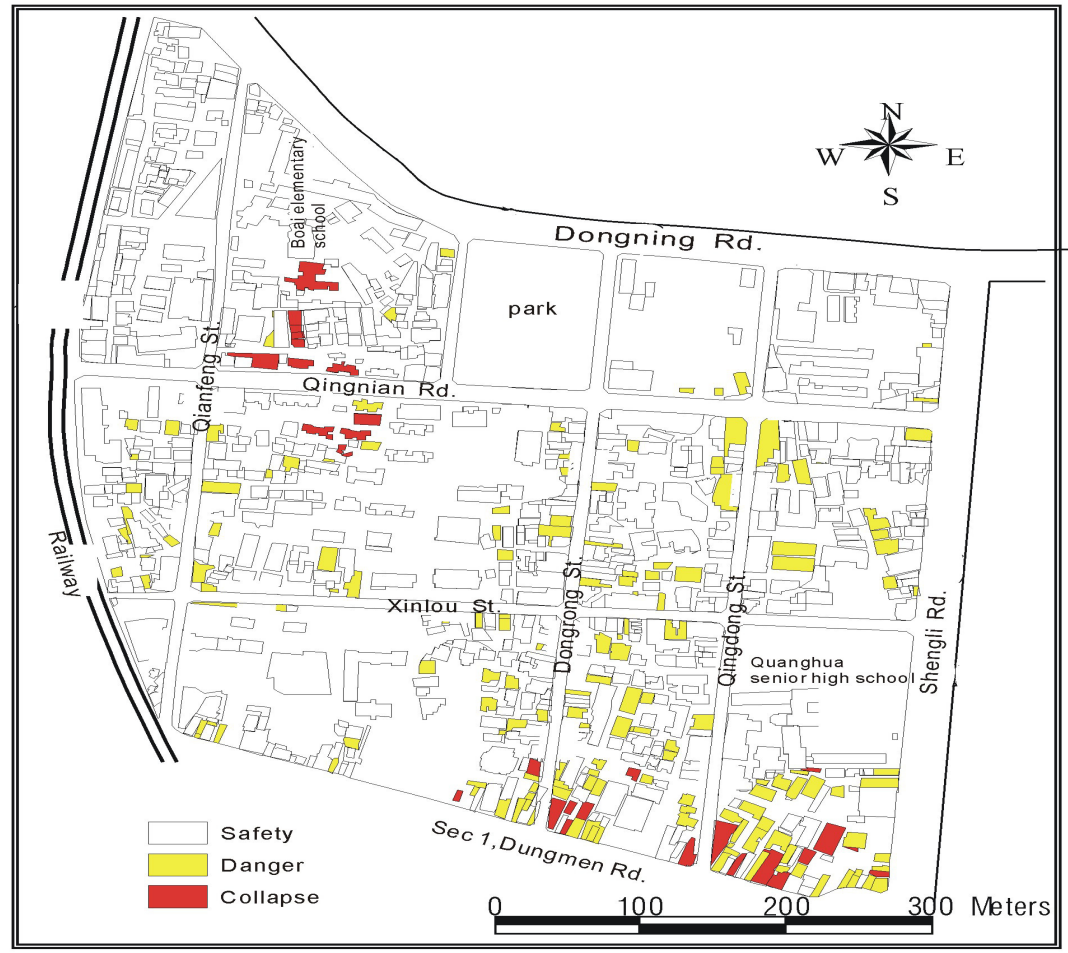

Figure 2: The hazard distribution diagram of the eastern part of Tainan City, Taiwan. 


\section{Conclusion and suggestion}

This model fits: (1) above 6-degree earthquake, (2) 2nd district in Taiwan earthquake categories, (3) non-hillside, non-basin effect and non-seaside areas, (4) middle and low-level buildings and (5) construction period in the last 10-20 years. The established model by Jwu-Shan town earthquake disaster data is as formula (3). The damaged buildings ratio is very close to the relational study [12]. The suggestion includes three parts as follows.

(1) Further studies can consider different earthquakes and different natural environments (basin effect, soil liquid etc.) to established models.

(2) The forecast methods of building earthquake disasters are various. Besides the logistic regression model, one can perhaps try to use other methods, such as the stepwise analysis method or fuzzy synthetic evaluation method of building earthquake disasters.

(3) This study model can be used in urban disaster protection planning, as the result is accurate $[13,14]$.

\section{References}

[1] Gao, J.-F., Disaster-prevention planning of urban anti-seismic. Fu-Wen of Taiwan Ltd, 1995 (in Chinese).

[2] Zhang, Z.-Y., Hazard analysis and its application in earthquake. Published by Tong-Ji University, 1995 (in Chinese).

[3] Hisomu, I., The basic framework and method for analysis of urban hazard in earthquake. The engineering of earthquake and shack of engineering, 19(1), pp. 70-75, 1999.

[4] Kazuki, N., The regional hazard and estimate of damages to the premise of disaster-prevention strategy. Speech materials of NAPHM, 1998.

[5] Yoshio, K., The evaluation of hazard ratio. The revival of safety city, pp. 35-39, 1999.

[6] Chen, L.-Q., Qiu, C.-P., The evaluation of urban inducing earthquake disaster. The preparatory office of Architecture \& Building Research Institute, 1994 (in Chinese).

[7] Takeo, K., The policy of urban disaster-prevention in Japan. 17th Chinese and Japan conference of technique in engineering (collection of essays on Building researches), Architecture \& Building Research Institute of Ministry of the Interior \& The Chinese Institute of Engineers, 1996.

[8] Okada, T., Promotion of seismic Retrofit of Building. The revival of safety city, pp. 9-15, 1999.

[9] Chen, L.-Q., Qiu, C.-P., The research on the item in the hazard of earthquake disasters. Architecture \& Building Research Institute of Ministry of the Interior, 1988 (in Chinese).

[10] Tsai, Y.-C., Chen, Q.-Q., The application and evaluation of the seismic resistance capacity of $R C$ building. The result report on case study of Architecture \& Building Research Institute of Ministry of the Interior, 1999 (in Chinese). 
[11] Jin, G.-L. et al., The forecast methods of damage by earthquake to the old house. Architectural science, 1, p91, 1985 (in Chinese).

[12] Hsieh, T.-C., Tsai, J.-S., Analytical Model for Building Damage Prediction in Urban Seismic Hazard Mitigation System. The Journal of Cheng Kung University, Science, Engineering and Medicine section, 32, pp. 35-39, 1997 (in Chinese).

[13] Chang, Y.-S. et al., The rebuilding outline planning after disaster in JwuShan Town. NCKU Research and Development Foundation, 2000 (in Chinese).

[14] Chang, Y.-S., The research on the planning of urban disaster-prevention. Architecture \& Building Research Institute of Ministry of the Interior, 1998 (in Chinese). 